\title{
Effect of Anger Management Educational Program on Mode of Anger Expression among Nursing Students
}

\section{Marwa Mohamed moustafa ${ }^{1}$, Ghada Mohamed Mourad ${ }^{2}$, Shewikar Tawfik EI Bakry ${ }^{3}$ and Fathyea Said Sayed ${ }^{4}$}

(1)Teacher at Al Mataria Health Nursing Institute, Egypt,(2)Professor of Psychiatric and Mental Health Nursing, Faculty of Nursing, Ain Shams University, Egypt,(3)Professor of Neuropsychiatry, Faculty of Medicine, Benha University, Egypt and (4)Assistant Professor of Psychiatric and Mental Health Nursing, Faculty of Nursing, Benha University, Egypt

\begin{abstract}
Background: Anger is a natural emotion that activates self-defense mechanisms to protect oneself in stressful situations. Anger can have negative effects on one's physical health and cause emotional problems such as depression, lowered quality of life and interpersonal problems. Aim of study: Was to assess effect of anger management educational program on mode of anger expression among nursing students. Design: Quasi-experimental research design. Setting: This study was conducted at Faculty of Nursing at Benha University. Study subjects: A convenient sample include nursing students at first academic year in faculty of nursing at Benha University. Tools of Data collection: Three tools were used: I: Structured interview questionnaire sheet include (socio demographic data, health characteristics of students \& family characteristics of students. II: Descriptive scale of expression of anger and III: Adolescent anger rating scale. Results: The majority of studied students had risky or inappropriate expression of anger preprogram, while postprogram the majority of them had non risky or appropriate expression of anger. More than two thirds of the studied students had high level of total adolescent anger rating scale pre-program, while, post program less than two thirds of them had low level total adolescent anger rating scale. Conclusion: There was a high statistically significant difference in total adolescent anger rating scale among studied sample pre -post program. Recommendations: Activating the role of media institutions in society to enrich individuals with the information necessary to understand the problem of anger and to identify treatment methods.
\end{abstract}

Keywords: Anger management, Educational program, Mode of anger Expression, Nursing student

\section{Introduction}

Anger is a perfectly normal feeling that all humans have, and is a natural response that occurs in various situations based on the interaction with the surroundings. Expression of anger plays an important role in maintaining human relationships and the method of expression varies greatly from frowning or showing irritation to being enraged (Masadeh et al., 2020).
Violent behavior and anger management related problems in school have rapidly increased among young adults worldwide. In many societies expressing one's emotions or thoughts is considered to represent excessively self-assertive behavior and thus, it is negatively viewed; consequently, individuals tend to suppress the anger. Anger or dysfunctional anger expression in college undergraduates are important issues that require active attention, as they are intimately related to serious 
mental health problems, such as suicidal ideation, depression, interpersonal relations problem and addiction, as well as to antisocial behaviors, such as dating violence (Sadagheyani et al., 2021).

Nursing students are the nucleus of the professional nurses of future who will interact with their colleagues and other health care professionals on a daily basis and provide the care for patients, their families and the acquisition of the assertion skills is considered the key to enhance personal competence and satisfying relationships (Ali, 2021).

In the nursing profession anger is a key emotional issue appearing due to stress. Anger might affect negatively to the quality of care that nursing professionals deliver. Hence, focusing nursing professionals/ students with high anger, nursing teaching must provide anger managing training. Anger managing plans must focus individual approaches of anger expression. For instance, a person who represses his/her anger might seem to calm however, experience delayed emotional recovery. The trait anger greatest powerfully affected anger-out. Such findings together advice that anger levels differ based on the method of expression employed (Jung \& Han, 2020).

Most anger-management programs for college students have been based on the cognitive behavioral model, incorporated arts, psychological approaches and mindfulness meditation into such programs. Anger is a concept that encompasses interactions between cognitive, emotional, behavioral components and specifically addressing these components as well as strengthening effective coping behaviors for anger overall may be important. Recent advances in positive psychology have highlighted that positive psychological features can constitute protective factors against anger (Amiri et al., 2020).

\section{Significance of the study}

The anger in nursing profession is a key emotional issue appearing due to stress. Anger might affect negatively to the quality of care that nursing professionals deliver. So, focusing on nursing students with high anger, anger managing plans must focus student approaches of anger expression. For instance, student who represses his anger might seem to calm however, experience delayed emotional recovery. The trait anger greatest powerfully affected anger-out (Jung \& Han, 2020).

\section{Aim of the study}

The aim of the current study was to assess effect of anger management educational program on mode of anger expression among nursing students.

\section{Research hypothesis:}

Anger management educational program would have a positive effect on mode of anger expression among nursing students.

\section{Subject and methods \\ Research design: \\ Quasi-experimental design (pre- program\& post-program) was utilized to conduct this study.}

\section{Setting:}

This study was conducted at the faculty of nursing at Benha University

\section{Sample:}

Convenience sample include nursing students at first academic year in Faculty of Nursing at Benha University. 


\section{Inclusion Criteria:}

- Students of the first undergraduate year.

- Students who are attends regularly

- Agree to participate in the study.

\section{Sample size:}

The sample size was calculated based on the study carried out by Sadagheyani et al., (2021). Based on the incidence of students' anger management skill preprogram was mean $24.91 \pm 2.83$ and at post program was mean $28.64 \pm 2.40$, statistical power of $85 \%$, confidence level (1-Alpha Error) 95\%, Alpha 0.05 and Beta 0.15 , the sample size determined for the group was 100 students.

\section{Tools of Data Collection:}

The data was collected using the following tools:

\section{Tool (1): Structured Interview Questionnaire.}

Socio-demographic characteristics of the studied students.

\section{Tool (2): Descriptive Scale of Expression of Anger (DSOEA)}

It was developed by Avrill (1982), and translated into Arabic by Abdel- Mooti \&Ali (2001). It assess five domains of anger expression, it was used in simple Arabic language and consist of 33 statements: anger severity, precipitating factors, associated reactive feelings, associated behaviors and mental evaluation of anger sources. This tool adapted by the researcher after reviewing literature in this field; the researcher edited and rephrasing items of tool to meet the aim of the study.

Scoring system: The scale is rated on (3) point likert scale ranging from $(0)=$ (rarely) to $(2)=($ always $)$.The scores will reversed for appropriate modes of anger so that a higher score will indicate more risky or inappropriate mode of anger expression.
The mode of anger expression was considered non risky or appropriate if the percent score was less than $60 \%$ and risky or in appropriate if $60 \%$ or more.

\section{Tool (3): Adolescent Anger Rating}

It was developed by Burney (2001); the scale assesses three modes of anger expression, it was used in simple Arabic language and consists of 41 statements: reactive anger, instrumental anger and anger control. This tool adapted by the researcher after reviewing literature in this field; the researcher edited and rephrasing items of tool to meet the aim of the study.

\section{Scoring system:}

Each items rated on (3) point likert scale ranging from $(0)=$ (rarely) to $(2)=$ (always).the scores of each mode will summed up and the total divided by the number of the items, giving a mean score for mode of anger expression used. A higher mean score reflects the mode of anger expression of the participant.

\section{Content validity \& Reliability:}

Testing validity of the proposed tool by using face and content validity face validity aimed to inspecting the items to determine whether the tools measure what supposed to measure. Content validity was conducted to determine whether the tool cover the aim. The validity of tools had done through five expertise Professors of Psychiatric \& Mental Health Nursing Specialties, from Banha and Ain Shams Universities. Testing reliability of proposed tools was done by Cronbach's alpha test. It was used to examine whether the questionnaire had internal consistency, anger rating scale reached (0.901) and expression of anger scale reached (0.889) which indicates acceptable reliability. 


\section{Pilot study}

A pilot study was carried out after the adaptation of the tools and before starting the data collection. It was conducted on $10 \%$ of the studied students 10 students from first grade. After obtaining the result of the pilot study, the necessary modifications of tools such as excluded questions, merged questions \& revised were done then final format was developed under the guidance of supervisors. All participants in the pilot study were excluded from the main study.

\section{Ethical Consideration:}

Before conducting the study the participants were assured about confidentiality and anonymity of their obtained information throughout the study. They were informed about their right to refuse to participate in the study and the right to withdraw from the study at any time.

\section{Field work:}

The study was carried out from the middle of October 2020 to middle of March 2021

\section{Development of management- educational program :}

The management-educational program was developed by the researcher after a thorough review of the related literatures and after making the pilot study. This program has a set of general objectives, and specific objectives for each session. The number of program's sessions was 10 sessions.

The $1^{\text {st }}$ session:

The main objective of this session was to help students to obtain an overview about the program.

The $2^{\text {nd }}$ session:

The main objective of this session was to help students to acquire knowledge about anger.

\section{The $3^{\text {rd }}$ session:}

The main objective of this session was to help students to recognize symptoms of anger and its physical and psychosocial effects of anger.

\section{The $4^{\text {th }}$ session:}

The main objective of this session was to help students to describe steps to improve self- esteem.

\section{The $5^{\text {th }}$ session:}

The main objective of this session was to help students to apply different effective communication skills

\section{The $6^{\text {th }}$ session:}

The main objective of this session was to help students to recognize and apply stress management techniques to decrease psychological problems (stress, anxiety, depression symptoms).

\section{The $7^{\text {th }}$ session:}

The main objective of this session was to help students to recognize and apply stress management technique

\section{The $8^{\text {th }}$ session:}

The main objective of this session was to help students to recognize and apply stress management technique to manage and decrease psychological problems

\section{The $9^{\text {th }}$ session:}

The main objective of this session was to help students to demonstrate steps for saying no assertively.

\section{The10 ${ }^{\text {th }}$ session:}

The main objective of this session was to help students to demonstrate steps of problem solving techniques.

The $11^{\text {th }}$ session:

The main objective of this session was to help students to summarize the knowledge had been acquired during the implementation of the program (the last session). 


\section{Implementation Phase:-}

This phase was beginning by data collection then implementation of psychoeducational intervention program.

\section{Methods of evaluation:-}

Feedback through: oral questions, redemonstration, positive participation, role play.

\section{Evaluation Phase (post-program).}

This phase used to evaluate the effect of anger management educational program on nursing students by comparing results pre and immediately post after implementation of educational program.

\section{Statistical analysis:}

All data were collected, coded, tabulated and subjected to statistical analysis. Statistical analysis was performed by statistical Package for Social Sciences (SPSS version 20.0). Descriptive statistics were applied in the form of mean and standard deviation for quantitative variables and frequency and percentages for qualitative variables. Qualitative categorical variables were compared using chi-square test. Statistical significance was considered at $p$-value $p \leq 0.05$, and considered highly statistically significance at $\mathrm{p}$-value $\mathrm{p} \leq$ 0.001 .

\section{Results}

Table (1): Illustrates that slightly more than one third $(35.5 \%)$ of the studied students aged between $18<19$ years with mean age $19.86 \pm 1.12$ and slightly less than three quarters were female $(72.0 \%),(65.0 \%)$ of them from rural area. Also the table clarified that more than half of them had 4to 6 family members with mean $4.38 \pm 1.45$, $50.0 \%$ of them had 3 and more friend with mean2.38 \pm 0.89 . For marital status, the majority of the studied students were single, the table also showed that about two thirds
(65.0) of them enter faculty through force by grades, the table also clarified that majority of them did not failure at faculty, while only $2.0 \%$ of them had failure more than one time.

Table (2): Presents that only $(6.0 \%)$ of the studied students had chronic diseases, the highest percentage $(50.0 \%)$ of the studied students had diseases is diabetes.

Also the table clarifies that the majority of them $(95.0 \%)$ had nonsmokers, more than one third $(35.0 \%)$ of them had walking was favorite sports, more than two fifths of them $(41.0 \%)$ had drawing is favorite hobbies.

Table (3): Shows that the majority $(86.0 \%)$ of studied students had risky or inappropriate expression of anger preprogram, while post-program the majority of them $(81.0 \%)$ had non risky or appropriate expression of anger. Moreover, there was a high statistically significant difference in total descriptive scale of expression of anger among studied students pre - post program at $\mathrm{p}$ value $(<0.001)$.

Figure (1): Displays that more than two thirds $(68.0 \%)$ of the studied sample had sever level of total adolescent anger rating scale pre-program, while, post program less than two thirds of them had low level total adolescent anger rating scale. 
Table (1): Distribution of the studied students according to their socio-demographic characteristics (personal characteristics) $(n=100)$.

\begin{tabular}{|c|c|c|}
\hline personal characteristics & $\mathbf{N}$ & $\%$ \\
\hline \multicolumn{3}{|l|}{ Age (Year) } \\
\hline $17>18$ & 13 & 13.0 \\
\hline $18>19$ & 35 & 35.0 \\
\hline $19>20$ & 27 & 27.0 \\
\hline $20>21$ & 25 & 25.0 \\
\hline $19.86 \pm 1.12$ & & \\
\hline \multicolumn{3}{|l|}{ Sex } \\
\hline Male & 28 & 28.0 \\
\hline Female & 72 & 72.0 \\
\hline \multicolumn{3}{|l|}{ Residence } \\
\hline Urban & 35 & 35.0 \\
\hline Rural & 65 & 65.0 \\
\hline \multicolumn{3}{|l|}{ No of family members } \\
\hline $1-3$ & 30 & 30.0 \\
\hline 4-6 & 56 & 56.0 \\
\hline+6 & 14 & $\mathbf{1 4 . 0}$ \\
\hline $4.38 \pm 1.45$ & & \\
\hline \multicolumn{3}{|l|}{ No of friends } \\
\hline 1 & 12 & 12.0 \\
\hline 2 & 38 & 38.0 \\
\hline 3 and more & 50 & 50.0 \\
\hline $2.38 \pm 0.89$ & & \\
\hline \multicolumn{3}{|l|}{ Marital status } \\
\hline Single & 88 & 88.0 \\
\hline Engaged & 9 & 9.0 \\
\hline Married & 3 & 3.0 \\
\hline \multicolumn{3}{|l|}{ Faculty choice } \\
\hline Own will & 26 & 26.0 \\
\hline Forced by grades & 65 & 65.0 \\
\hline Forced by family & 9 & 9.0 \\
\hline \multicolumn{3}{|l|}{ Failure at faculty } \\
\hline Never & 92 & 92.0 \\
\hline Once & 6 & 6.0 \\
\hline More than one & 2 & 2.0 \\
\hline
\end{tabular}


Table (2): Distribution of the studied students according to their health characteristics $(\mathbf{n}=\mathbf{1 0 0})$.

\begin{tabular}{|l|l|l|}
\hline Health characteristics & N & $\%$ \\
\hline Have chronic diseases & 6 & 6.0 \\
\hline Yes & 94 & 94.0 \\
\hline No & \multicolumn{2}{l|}{} \\
\hline If yes, what is this (n=6) & 1 & 16.7 .0 \\
\hline Hypertension & 2 & 33.3 .0 \\
\hline Hypotension & 3 & 50.0 \\
\hline Diabetic & \multicolumn{2}{l|}{} \\
\hline Smoking status & \multicolumn{3}{l|}{} \\
\hline Nonsmoker & 95 & 95.0 \\
\hline Ex-smoker & 2 & 2.0 \\
\hline Current smoker & 3 & 3.0 \\
\hline Favorite sports & \multicolumn{2}{l|}{} \\
\hline Football & 26 & 26.0 \\
\hline Swimming & 24 & 24.0 \\
\hline Walking & 35 & 35.0 \\
\hline Basketball & 15 & 15.0 \\
\hline Favorite hobbies & \multicolumn{2}{|l}{} \\
\hline Writing & 8 & 8.0 \\
\hline Musical & 19 & 19.0 \\
\hline Trips & 32 & 32.0 \\
\hline Drawing & 41 & 41.0 \\
\hline & \multicolumn{2}{l}{} \\
\hline
\end{tabular}

Table (3): Comparison between the studied students at pre and post program regarding to their total descriptive scale of expression of anger $(n=100)$.

\begin{tabular}{|c|c|c|c|c|c|c|}
\hline \multirow{3}{*}{$\begin{array}{l}\text { Total descriptive scale of } \\
\text { Expression of anger }\end{array}$} & \multirow{2}{*}{\multicolumn{2}{|c|}{ Pre- program }} & \multirow{2}{*}{\multicolumn{2}{|c|}{ Post- program }} & \multicolumn{2}{|c|}{ T- test } \\
\hline & & & & & $\mathbf{T}$ & p-value \\
\hline & $\mathbf{N}$ & $\%$ & $\mathbf{N}$ & $\%$ & & \\
\hline Non risky or appropriate & 14 & 14.0 & 81 & 81.0 & & \\
\hline Risky or inappropriate & 86 & 86.0 & 19 & 19.0 & 34.19 & $.000 * *$ \\
\hline
\end{tabular}




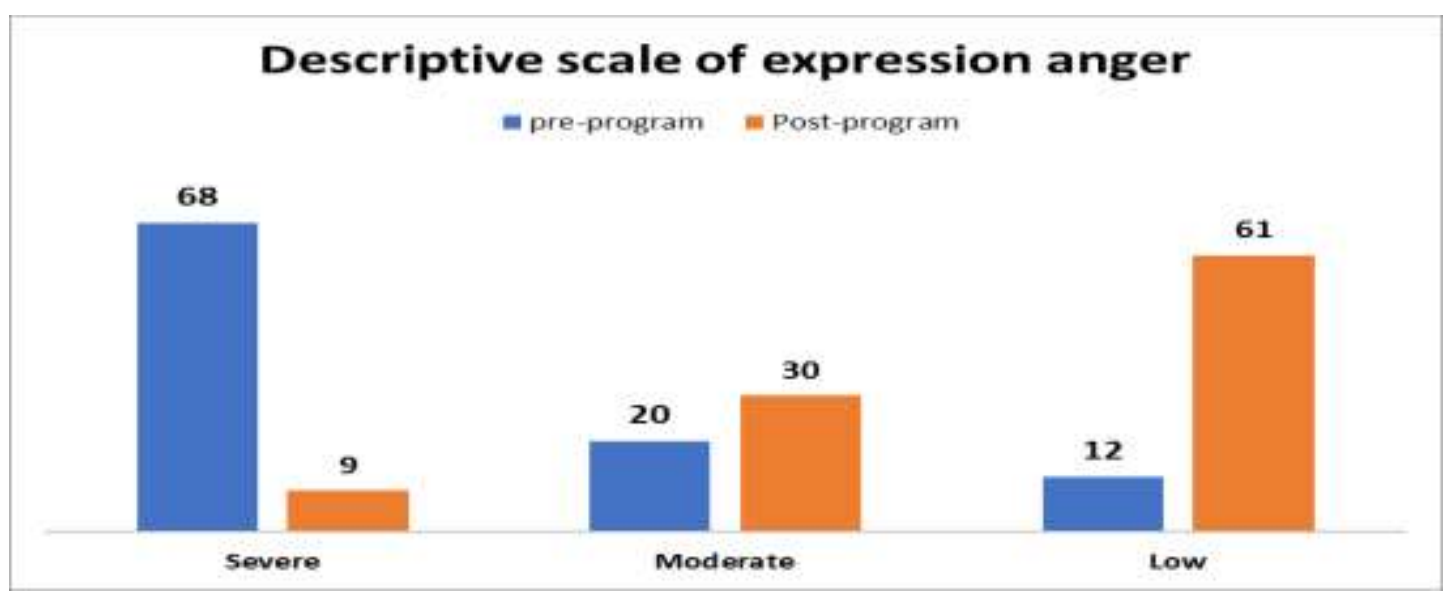

Figure (1): Distribution of studied students at pre and post preprogram regarding to their total adolescent anger rating scale $(n=100)$.

\section{Discussion:}

The present study revealed that the highest percentage of the studied nurses were females, this finding in same line with study Han et al., (2015) who conducted study about "Anger expression types and interpersonal problems in nurses" and reported that the majority of the studied nurses were females. This result may be due to the public generally perceives nursing as a feminine profession and this perception has deterred many qualified and interested males from taking up nursing as a profession, as any man entering nursing is generally seen as acting against societal norms.

Regarding residence, the present study revealed that about two thirds of studied students were lived in rural areas, it may be due to people in rural area increase in awareness to nursing profession, women in rural area are independent but seeking for job to earn money but in urban areas cultures were prevented from work as nurse.

This finding not consistent with the study conducted by Bigbee \& Mixon, (2013) who assessed recruitment and retention of rural nursing students and stated that students from rural backgrounds are more challenged in adapting to the largゆisobssioncademic environment, often far from family and community supports.

The present study revealed that that the majority of the studied students had single, This result might due to most nursing student refuse marriage during study to become focus on study only and academic achievement. This finding consistent with Han et al.,(2015) who conducted study about "Anger expression types and interpersonal problems in nurses" and said that the highest percentage of the studied sample were single.

Regarding Faculty choice, the present study showed that the highest percentage of the students nurses enter faculty of nursing due to their scores, This might due to firstly, most student had hope to join the faculty of medicine not achieved this hope so that join faculty of nursing is one of faculties of top in Egypt and work on medical field. The second reason was the personal ability as the stress management, motivation and perseverance. Finally, The student decide to choose or not choose nursing was significantly influenced by factors like previous academic achievement, mother's occupation, the school teachers, past experiences with career 
activities, security of employment, a steady income and working in hospital, furthermore knowledge about the career could be the main factor to influence student's decision to study nursing.

This study consistent with Mooney et al., (2008) assessed impressions of nursing before exposure to the field stated that majority of the studied students didn't have nursing as their first choice career. Some preferred careers in alternative healthcare professions like occupational therapy, medicine or physiotherapy, some were interested in teaching but due to insufficient grades, they choose nursing.

This result is not agreement with Jun, (2016) who conducted study about "Anger expression, self-efficacy and interpersonal competency of Korean nursing students" and reported that highest percentage of the studied reason for entering was guaranteed employment. In same line Eley et al., (2012) who assessed personality traits and reasons for entering nursing, found that nursing students choose to study nursing because of the opportunity for caring and that it was their vocation in life which were congruent with the character and temperament found in the students. Also Gutierrez et al., (2010) assessed factors influencing the choice of nursing studies, stated that, students need job security, knowing that after studying it is easy to acquire a job, personal contact with the healthcare world or with someone in the healthcare world influences the decision to choose nursing career. If one experiences a loss of a loved one or near loss of a loved one, this would influence student in choosing nursing as a career.

Regarding chronic diseases, the present study show only $(6.0 \%)$ of the studied students had chronic diseases, and most prevalent diseases among them were diabetes. This result might due to spread of eating fast food among students and adolescents and their lack of knowledge of its harmful effects. These result in contradiction with the study finding of Gazibara et al., (2018) who conducted study about "Chronic diseases among university students: prevalence, patterns and impact on health-related quality of life" and reported that (14.0\%) of the studied sample had chronic disease and most prevalent disease was asthma.

Concerning Smoking status, it noticed most of the studied students nurses did not smoke. This result might due to studied students know dangerous and consequences of smoking and parent supervision, this result matched with Jang, \& Jeon, (2017) who performed study entitled "A study on anger expression mode of nursing students" and proved that most of the studied student nurses did not smoke.

Regarding to feeling of anger, the current result showed that majority of the studied students had inappropriate mode of anger expression to feeling preprogram, while after application of the program the most of them become had appropriate mode of anger expression to precipitating factors. Furthermore, there was a statistically significant difference in feeling of anger among studied sample pre -post program. This result might due to effective of educational program. These findings agreement with result of Lotfalizadeh et al., (2020) who conducted study about "The effect of anger management skills training on anger status of the people with HIV" and reported that reduction in mean scores of feelings subscale of anger with statistically 
significant difference in feeling of anger among studied sample pre -post program.

\section{Regarding severity of anger} expression, the present study revealed that decrease severity of anger expression among studied student nursing after application of educational program and there was a high statistically significant difference in severity of anger expression among studied students pre -post program. This finding can be justified by effects of the educational approaches\& behavioral techniques on reducing cognitive distortions and anger. This result similar result of Serin and Genç, (2011), who conducted study about "Anger management education program among adolescents effect on their skills" and showed that effective in anger management on reducing severity of anger expression.

The current study showed that more than two thirds of the studied sample had sever level of total adolescent anger rating scale pre-program, while, post program less than two thirds of them had low level total adolescent anger rating scale. Furthermore, there was a high statistically significant difference in total adolescent anger rating scale among studied sample pre -post program p value $(<0.001)$.

This result might due to effectiveness of the educational program to decrease the level of anger among studied students.

These findings matched with Jeyasutha, (2014) who carried out study about "Effectiveness of anger management program among early adolescents in a selected school" and reported that there was a high statistically significant difference in total adolescent anger rating scale among studied students pre -post program p value $(<$ $0.001)$.level of anger level in pre and post- program score among studied students, In preprogram about one third of studied students were having moderate anger level, about two third of them were having high anger level. While, in post-program, majority of studied students were having moderate anger level, $(6.7 \%)$ were having high anger level.

On other hand, the finding contrast with Hong, \& Kim, (2020) who conducted study about "Effects of a psychological management program on subjective happiness, anger control ability and gratitude among late adolescent males in Korea" and reported that the mean total anger score decreased post application program, with no significant difference between pre and post program. This difference between studies might due to number of sessions in the program methodology were inappropriate for decreasing anger.

\section{Conclusion}

There were significant improvement in expression of anger between studied students immediately post educational program implementation. Moreover, there were significant improvements in level of total student's anger rating scale due to the effect educational of program.

\section{Recommendations}

1- Researchers should continuously create emotional awareness program for faculty of nursing students.

2- Mental health consultation should be facilitated to encourage nursing students seek professional assistance when personal issues distress triggered by academic or clinical experiences and that influence student nurse well- being.

3- Performing seminars that address the problem of anger and show students the best ways to overcome their anger. 
4-Presenting illustrated scientific materials and give educational program in students curriculum aimed to reducing the problem of anger among students.

\section{References}

Ali, H. M. Z. (2021). Self-differentiation as an intermediate variable between anger management and neurotic perfectionism among high achievers "a psychological study of the rights of special education". International Journal of Human Rights in Healthcare.

Abdel-Mooti, H.\& Ali, A. (2001). Development,translation and score validation of descriptive scale of expression of anger (DSOEA).Cairo:Al- Nahada AlMasria Library.

Amiri, F., Moslemifar, M., Showani, E., \& Panahi, A. (2020). Effectiveness of forgiveness therapy in treatment of symptoms of depression, anxiety, and anger among female students with love Trauma Syndrome. Journal of Advanced Pharmacy Education \& Research| Jan-Mar, 10(S1), 99.

Averill, J. (1982): Anger and aggression, an essay of an emotion, New York:Springer Velage Publishers.

Burney, D. (2001). Adolescent anger rating scale:professionalManual.Florida:Psycholog ical Assessment Resources:Lutz.

Bigbee, J. \& Mixon, D. (2013). "Recruitment and Retention of Rural Nursing Students: A Retrospective Study". Rural and Remote Health, 13, 2486-1 2486-10.

Eley D., Eley R., Bertello M. \& RogersClark C. (2012). Why did I become a nurse? Personality traits and reasons for entering nursing. Journal of Advanced Nursing 68(7), 1546-1555.

Gazibara, T., Pekmezović, T., Popović, A., Paunić, M., \& Kisić-Tepavčević, D. (2018). Chronic diseases among university students: prevalence, patterns and impact on health-related quality of life. Vojnosanitetski pregled, 75(12), 1178-1184.

Gutierrez, San. R. S., Maranon, A. A., Poch, B. E. \& Prat, V. O. (2010). Factors influencing the choice of nursing studies [Spanish]. Enfermeria Clinica. July- Aug (40), 36-42.

Han, A., Won, J., Kim, O., \& Lee, S. E. (2015). Anger expression types and interpersonal problems in nurses. Asian nursing research, 9(2), 146-151.

Hong, J. E., \& Kim, M. (2020). Effects of a psychological management program on subjective happiness, anger control ability, and gratitude among late adolescent males in Korea. International journal of environmental research and public health, 17(8), 2683.

Jung, H. O., \& Han, S. W. (2020). The Effects of MBTI applied Peer-to-Peer Relationship Improvement Training Programs on Self-Esteem, Depression, and Anger of Korean Female Students at Nursing Vocational High Schools. Indian Journal of Public Health Research \& Development, 11(6).

Jun, W. H. (2016). Anger expression, selfefficacy and interpersonal competency of Korean nursing students. International nursing review, 63(4), 539-546.

Jang, H. J., \& Jeon, M. K. (2017). A study on anger expression mode of nursing 
students. Research Journal of Pharmacy and Technology, 10(7), 2271-2273.

Jeyasutha, R. (2014). Effectiveness of anger management programme among early adolescents in a selected school, Thoothukudi-True Experimental Study. Int J Compr Nurs, 1, 11-7.

Lotfalizadeh, M., Miri, S., Foroughameri, G., \& Farokhzadian, J. (2020). The effect of anger management skills training on anger status of the people with HIV. Perspectives in psychiatric care, 56(3), 605-613.

Masadeh, R., Masadeh, O., Jarrah, S., AlAzzam, M., \& Alhalaiqa, F. (2020). Effect of aggression management training on perceived stress levels of nurses working in mental health care settings in Jordan. Journal of Psychosocial Nursing and Mental Health Services, 58(10), 32-38.

Mooney, M., Dobia, B., Yeung, A. S., Barker, K. L., Power, A., \& Watson, K. (2008). Positive Behaviour for Learning: Investigating the Transfer of a United States System into the New South Wales Department of Education and Training Western Sydney Region Schools: Report, University of Western Sydney, 16(1), p.p. 21-24.

Serin N.\& Genç, H. (2011). Anger management education program among adolescents effect on their skills. Education and Science; (6):--p.p.54-236.

Sadagheyani, H. E., Tatari, F., Raoufian, H., Salimi, P., \& Gazerani, A. (2021). The effect of multimedia-based education on students' anger management skill. Educación Médica, 22(3), 149-155. 
تأثير برنامج تعليمي لإدارة الغضب على سبل التعبيرعن الغضب بيـن طـلاب التمريض

مروة محم مصطفى - غادة محم مر اد - شويكار توفيق البكرى فتحية سعيد سيد

الغضب هو شعور طبيعي تمامًا لدى جميع البشر وهو إستجابة طبيعية تحدث في مواقف مختلفة بناءً

على التفاعل مع البيئة المحيطة. يلعب التعبير عن الغضب دورًا مهمًا في الحفاظ على العلاقات الإنسانية. الغضب في مهنة التمريض هو قضية رئيسية نظهر بسبب الإجهاد، قد يؤثر الغضب سلبًا على جودة الرعاية

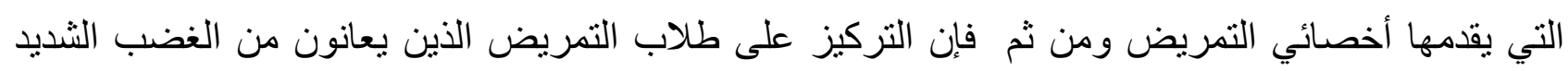

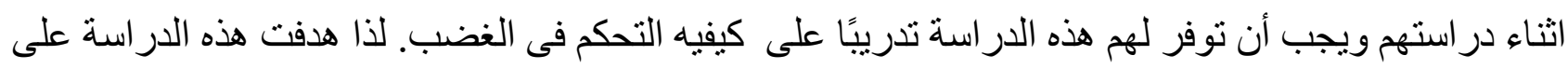

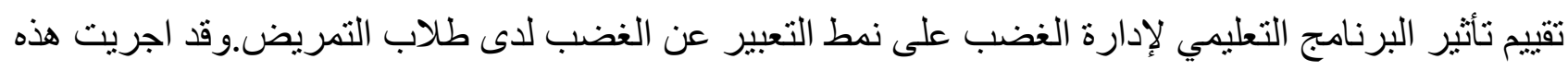

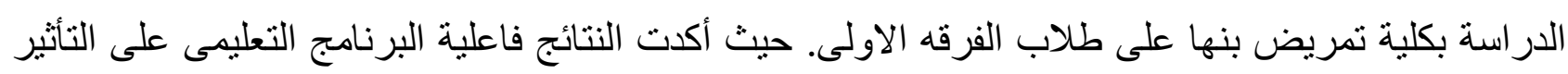

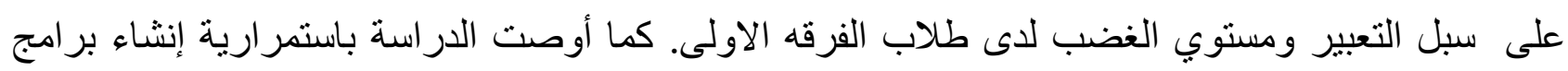

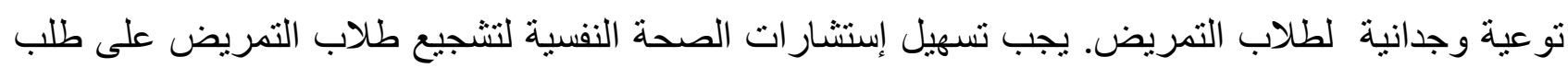

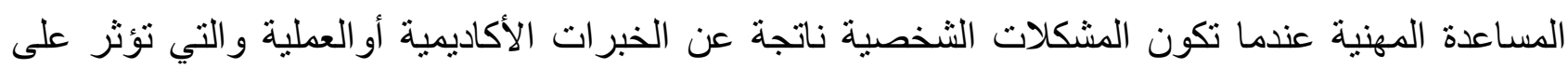
رفاهية طلاب التمريض. 